\title{
Is disability pension a risk indicator for future need of psychiatric healthcare or suicidal behavior among MS patients- a nationwide register study in Sweden?
}

\author{
Charlotte Björkenstam ${ }^{1 *}$, Petter Tinghög ${ }^{1}$, Philip Brenner ${ }^{2}$, Ellenor Mittendorfer-Rutz ${ }^{1}$, Jan Hillert²,
} Jussi Jokinen ${ }^{2}$ and Kristina Alexanderson ${ }^{1}$

\begin{abstract}
Background: Mental disorders and suicidal behavior are common in patients with multiple sclerosis (MS), they also carry a higher risk of disability pension (DP). Our aim was to investigate if DP and other factors are associated with psychiatric disorders and suicidal behavior among MS patients, and whether DP is a stronger risk indicator among certain groups.

Method: A prospective population-based cohort study with six-year follow-up (2005-2010), including 11346 MS patients who in 2004 were aged 16-64 and lived in Sweden. Incidence rate ratios (IRR) with $95 \%$ confidence intervals (Cl) were calculated.

Results: MS patients on DP had a modestly higher risk of requiring psychiatric healthcare, IRR: 1.36 (95 \% Cl: 1.181.58). MS patients with previous psychiatric healthcare had a higher IRR for both psychiatric healthcare and suicidal behavior; 2.32 (2.18-2.47) and 1.91 (1.59-2.30), respectively. DP moderated the association between sex and psychiatric healthcare, where women on DP displayed higher risk than men, $X^{2} 4.74(p=0.03)$.
\end{abstract}

Conclusion: The findings suggest that losing one's role in work life aggravates rather than alleviates the burden of MS, as MS patients on DP seem to have a higher need for psychiatric healthcare, especially among women; which calls for extra awareness among clinicians.

Keywords: Multiple sclerosis, Disability pension, Suicidal behavior, Psychiatric healthcare, Sick leave

\section{Background}

Multiple sclerosis (MS) is a disabling demyelinating autoimmune disorder and is the most common cause of neurological disability among young adults [1]. Worldwide, approximately 2.5 million people are affected [2]. The etiology of MS is still largely unknown but both genetic and environmental factors have been shown to be of importance [3]. A recent study showed that as many as $62 \%$ of MS patients of working ages are on disability pension (DP) [4]. It is also well established that the risk of developing mental disorders is higher in

\footnotetext{
* Correspondence: charlotte.bjorkenstam@ki.se

'Division of Insurance medicine, Department of Clinical Neuroscience, Karolinska Institutet, SE-171 77 Stockholm, Sweden

Full list of author information is available at the end of the article
}

patients with MS [5], as is suicide attempts and suicide $[6,7]$. Nevertheless, it is still unknown if MS patients on DP have a higher risk of mental disorders and suicidal behavior.

The higher risk of mental disorders in MS patients could reflect direct or indirect effects of an autoimmune disorder on the central nervous system, it could be due to medications used in the treatment, it could be due to the psychological impact of suffering from a chronic disease, or other mechanisms could be at hand [8]. Mental disorders remain under-diagnosed and undertreated in MS patients and MS patients at lower socioeconomic levels have the highest degree of comorbidity with depression [9]. The reported prevalence of depression among MS patients varies, however, widely [10]. 
Depression is probably the most common underlying factor for both psychiatric healthcare and suicidal behavior in these patients. Nevertheless, more knowledge is warranted on how these associations are distributed among MS patients as a basis for intervention.

There is only limited knowledge on how sociodemographics or DP status among MS patients are associated with psychiatric healthcare or with suicidal behavior. Moreover, no studies have so far investigated whether socio-demographic factors' associations with psychiatric health are moderated by DP status among MS patients. In this study the aims were to:

- Investigate if DP and socio-demographic and clinical factors are associated with future psychiatric healthcare and suicidal behavior among MS patients.

- Analyze whether DP moderates the associations between different socio-demographics and clinical factors and psychiatric healthcare and suicidal behavior.

\section{Methods \\ Study population}

This is a population-based prospective cohort study with a six-year follow-up period; 2005-2010. We included all individuals who 31 December 2004 were 16-64 years of age, lived in Sweden, and, according to the Swedish patient register (PAR), had been diagnosed with MS (ICD8: 340, ICD-9: 340, ICD-10: G35) sometime between 1969 and 2004. This generated 11346 MS patients, whereof 7990 women (70 \%) and 3356 men. PAR is held by the National Board of Health and Welfare and contains information on in-patient care since 1964 and specialized out-patient care since 2001. Our MS patients were thus selected from the in-patient care register between 1969 and 2004 and from the out-patient care register between 2001 and 2004. The unique personal identity number assigned to each Swedish citizen or permanent resident was used to link information from different registers [11].

\section{Exposures}

Disability pension, which in Sweden can be granted to individuals who, due to disease or injury, have permanently reduced work capacity, even if they do not have previous income from work. DP covers approximately $65 \%$ of the lost income, up to a limit. Information on DP in 2004 was obtained from the National Social Insurance Agency's MiDAS database.

\section{Socio-demographics in 2004 and clinical factors}

Educational level was obtained from Statistics Sweden's Longitudinal Integration Database for Health Insurance and Labor Market Studies (LISA), and classified into: 1) $\leq 9$ years, compulsory school, 2) 10-12 years, senior high school), and 3) >12 years, college or university.

Age was categorized into six groups: 16-29, 30-39, 40-49, 50-59, and 60-64.

Country of birth, categorized into three groups (Sweden, other Nordic countries, and the rest of the world) was also obtained from LISA, as was marital status, dichotomized as married/not married.

The decade when the patient was diagnosed with MS, was categorized into four groups: 70s (including 1969), $80 \mathrm{~s}, 90 \mathrm{~s}$, and the $21^{\text {st }}$ century. Also previous in- or outpatient specialized healthcare for psychiatric disorders (coded according to the International Classification of Disease (ICD) as ICD-9: 290-319 or ICD-10: F00-F99), as main or secondary diagnosis, categorized as at least one such hospitalization or out-patient visit between 1987 and 2004 was analyzed.

\section{Outcomes}

We analyzed two separate outcomes: psychiatric healthcare and suicidal behavior. Psychiatric healthcare was defined as having a psychiatric diagnosis in either in- or specialized out-patient care during the follow-up period 2005-2010. Suicidal behavior was also measured during 2005-2010 and included both suicide attempts and completed suicides. Information on suicide attempts was obtained from PAR and defined as having a diagnosis of self-inflicted harm (ICD-10: X60-X84). Suicide was defined as having suicide as the underlying cause of death in the Causes of Death Register (ICD-10: X60-X84) or as death with undetermined intent (ICD-10: Y10-Y34). With our definition of suicide including deaths with undetermined intent, our aim was to reduce spatial and secular trends in detecting and classifying suicide [12].

\section{Statistical analyses}

We used Poisson regression analyses to estimate associations between DP and different socio-demographics and clinical factors and the two outcomes; psychiatric healthcare and suicidal behavior. As a measure of the relative occurrence of psychiatric healthcare and suicidal behavior we used the incidence rate ratios (IRR) and adjusted for all socio-demographics in 2004 and the clinical factors (mentioned above). By adding up the years the individuals were alive and living in Sweden (from the LISA database) during the follow-up period we assessed person-years at risk. All individuals were followed from 1 January 2005 until the end of follow-up or until they experienced the respective event, emigrated, or died, whichever came first. SAS GENMOD procedure was used to calculate IRR and $95 \%$ confidence intervals (CIs) for psychiatric healthcare and suicidal behavior, respectively. 
We also performed a sensitivity analysis where we excluded MS patients who had been on DP prior to 2003. In this analysis we compared MS patients who only recently (in 2003 or 2004) had been granted DP to MS patients not on DP, and censoring MS patients who were granted DP during followup. Further, we ran an extra analysis where we excluded MS patients with a history of psychiatric care.

We constructed one model including all main effects and six interaction terms of interest to determine whether different background factors moderated the association between DP and the outcomes. Effect modifications were evaluated with Wald $\mathrm{X}^{2}$ tests. Statistical significance was defined as $\mathrm{p}<0.05$. All analyses were carried out in the statistical software SAS 9.1 (SAS Institute Inc. Cary, NC, USA).

\section{Ethics statement}

The study population was based on linkage of several public national registers. Ethical vetting is always required when using register data in Sweden. The ethical vetting is performed by regional ethical review boards and the risk appraisal associated with the Law on Public Disclosure and Secrecy is done by data owners. The ethical review boards can however waive the requirement to consult the data subjects (or in case of minors/ children the next of kin, careers or guardians) directly to obtain their informed consent, and will often do so if the research is supported by the ethical review board and the data has already been collected in some other context. According to these standards in Sweden this project

Table 1 Descriptive data ( $n$ and \%) of the cohort of 11346 patients with multiple sclerosis (MS), among all, those not on disability pension (DP) and on DP in 2004, regarding future psychiatric healthcare and suicidal behavior, respectively

\begin{tabular}{|c|c|c|c|c|c|c|c|c|c|}
\hline \multirow{2}{*}{\multicolumn{2}{|c|}{ DP }} & \multirow[b]{2}{*}{ No DP } & \multirow[b]{2}{*}{ Total } & \multicolumn{3}{|c|}{ Psychiatric healthcare in 2005-2010 } & \multicolumn{3}{|c|}{ Suicidal behavior 2005-2010 } \\
\hline & & & & DP & No DP & Total & $\mathrm{DP}$ & No DP & Total \\
\hline All & $6399(56)$ & $4947(44)$ & 11346 & $678(61)$ & $426(39)$ & 1104 & $78(66)$ & $40(34)$ & 118 \\
\hline \multicolumn{10}{|l|}{ Sex } \\
\hline Women & $4659(58)$ & $3331(42)$ & 7990 & $522(65)$ & $275(35)$ & 797 & $57(68)$ & $27(32)$ & 84 \\
\hline Men & $1740(52)$ & $1616(48)$ & 3356 & $156(51)$ & $151(49)$ & 307 & $21(62)$ & $13(38)$ & 34 \\
\hline \multicolumn{10}{|c|}{ Decade of MS Diagnosis } \\
\hline $70 \mathrm{~s}$ & $404(68)$ & $191(32)$ & 595 & $35(70)$ & $15(30)$ & 50 & $8(100)$ & $0(0)$ & 8 \\
\hline $80 \mathrm{~s}$ & $1192(77)$ & $351(23)$ & 1543 & $115(78)$ & $33(22)$ & 148 & $10(71)$ & $4(29)$ & 14 \\
\hline $90 \mathrm{~s}$ & $1986(74)$ & $708(26)$ & 2694 & $213(81)$ & 49 (19) & 262 & $23(82)$ & $5(18)$ & 28 \\
\hline 21st century & 2817 (43) & 3697 (57) & 6514 & 315 (49) & $329(51)$ & 644 & $37(54)$ & $31(46)$ & 68 \\
\hline \multicolumn{10}{|l|}{ Age 2004} \\
\hline $16-29$ & $121(16)$ & $644(84)$ & 765 & $37(33)$ & $76(67)$ & 113 & $3(37)$ & $8(73)$ & 11 \\
\hline 30-39 & $657(31)$ & 1464 (69) & 2121 & $94(42)$ & $129(58)$ & 223 & $8(44)$ & $10(56)$ & 18 \\
\hline $40-49$ & $1536(51)$ & 1474 (49) & 3010 & $201(62)$ & $123(38)$ & 324 & $25(61)$ & $16(39)$ & 41 \\
\hline 50-59 & $2746(72)$ & $1087(28)$ & 3833 & $254(76)$ & 79 (24) & 333 & $30(86)$ & $5(14)$ & 35 \\
\hline 60-64 & 1339 (83) & $278(17)$ & 1617 & $92(83)$ & $19(17)$ & 111 & $12(92)$ & $1(8)$ & 13 \\
\hline \multicolumn{10}{|c|}{ Psychiatric diagnosis before 2005} \\
\hline Yes & $1594(70)$ & $699(30)$ & 2293 & $403(69)$ & $177(31)$ & 580 & $46(78)$ & $13(22)$ & 59 \\
\hline No & $4805(53)$ & $4248(47)$ & 9053 & $275(52)$ & $249(48)$ & 524 & $32(54)$ & $27(46)$ & 59 \\
\hline \multicolumn{10}{|c|}{ Educational level 2004} \\
\hline$\leq 9$ years & $1580(73)$ & $599(27)$ & 2179 & $150(70)$ & $63(30)$ & 213 & $16(84)$ & $3(16)$ & 19 \\
\hline $10-12$ years & $3504(57)$ & $2654(43)$ & 6158 & $383(62)$ & $233(38)$ & 616 & $56(64)$ & $31(36)$ & 87 \\
\hline$>12$ years & $1315(44)$ & $1694(56)$ & 3009 & $145(53)$ & $130(47)$ & 275 & $6(50)$ & $6(50)$ & 12 \\
\hline \multicolumn{10}{|c|}{ Country of birth } \\
\hline Sweden & $5831(56)$ & $4496(44)$ & 10327 & $599(62)$ & $373(38)$ & 972 & $71(67)$ & $35(33)$ & 106 \\
\hline Other Nordic & $222(64)$ & $126(36)$ & 348 & $28(72)$ & $11(28)$ & 39 & $4(67)$ & $2(33)$ & 6 \\
\hline Other World & $346(52)$ & $325(48)$ & 671 & $51(55)$ & $42(45)$ & 93 & $3(50)$ & $3(50)$ & 6 \\
\hline \multicolumn{10}{|c|}{ Marital Status 2004} \\
\hline Married & $3123(57)$ & $2371(43)$ & 5494 & $239(58)$ & $176(42)$ & 415 & $24(65)$ & $13(35)$ & 37 \\
\hline Unmarried & $3276(56)$ & $2576(44)$ & 5852 & $439(64)$ & $250(36)$ & 689 & $54(67)$ & $27(33)$ & 81 \\
\hline
\end{tabular}


has been evaluated and approved by the Regional Ethical Review Board of Karolinska Institutet, Stockholm, Sweden.

\section{Results}

In our cohort of 11346 MS patients of working ages (70 \% women), 6399 were on DP at baseline 2004 (Table 1). As expected, it was more common among MS patients on DP to be older, $21 \%$ was in the oldest age group (60-64 years), compared to $6 \%$ among MS patients not on DP. Low educational level was also more common among MS patients on DP in 2004, $25 \%$ compared to $12 \%$ among MS patients who were not on DP. In total, 1104 individuals (10\%) received psychiatric healthcare and 118 individuals $(1 \%)$ had suicidal behavior during the follow-up period, 2005-2010. The rate of women was very similar in the two outcome groups as in the whole cohort, $72 \%$ and $71 \%$ related to future psychiatric health care and suicidal behavior, respectively, compared to $70 \%$ women in total. Among MS patients on DP in 2004, $11 \%$ had psychiatric healthcare during follow-up compared to $9 \%$ of those not on DP. It was more common to have had psychiatric healthcare before 2005 in the two outcome groups, $53 \%$ of the psychiatric healthcare group and $50 \%$ of the suicidal behavior group compared to $14 \%$ among MS patients not on DP. Previous psychiatric health care was also more common among MS patients on DP, $25 \%$, compared to $14 \%$ among patients not on DP.

When we calculated multi-adjusted IRR for DP and the different socio-demographics and clinical factors, previous psychiatric healthcare was statistically significant for both outcomes; psychiatric healthcare IRR: 2.32 (95 \% CI: 2.18-2.47) and suicidal behavior IRR: 1.91 (1.59-2.30) (Table 2). MS patients on DP displayed higher IRR for psychiatric healthcare: 1.36 (1.18-1.58). We found a tendency towards a higher risk for suicidal behavior, however, not statistically significant IRR: 1.46 (0.95-2.26). Individuals born outside of the Nordic countries had higher risk for psychiatric healthcare; IRR: 1.29 (1.08-1.54) as did the youngest patients, aged 16-29;

Table 2 Adjusted $^{a}$ incidence rate ratios (IRR) with $95 \%$ confidence intervals (CI) for psychiatric healthcare and suicidal behavior, respectively, during five-year follow up among 11346 MS patients of working ages

\begin{tabular}{|c|c|c|c|}
\hline & & Psychiatric healthcare & Suicidal behavior \\
\hline & & IRR (95 \% Cl) & IRR $(95 \%$ Cl) \\
\hline \multirow[t]{2}{*}{ Sex } & $\mathrm{F}$ & $0.95(0.89-1.01)$ & $0.98(0.80-1.20)$ \\
\hline & M & 1 (REF) & 1 (REF) \\
\hline \multirow[t]{2}{*}{ DP 2004} & Yes & $1.36(1.18-1.58)$ & $1.46(0.95-2.26)$ \\
\hline & No & 1 (REF) & 1 (REF) \\
\hline \multirow[t]{3}{*}{ Country of birth } & Nordic & $0.90(0.72-1.13)$ & $1.36(0.74-2.49)$ \\
\hline & World & $1.29(1.08-1.54)$ & $0.85(0.46-1.55)$ \\
\hline & Swe & 1 (REF) & 1 (REF) \\
\hline \multirow[t]{5}{*}{ Age 2004} & $16-29$ & $1.77(1.49-2.10)$ & $1.44(0.84-2.48)$ \\
\hline & $30-39$ & 1.19 (1.05-1.35) & $0.88(0.57-1.35)$ \\
\hline & $40-49$ & 1.07 (0.96-1.19) & $1.23(0.89-1.70)$ \\
\hline & $50-59$ & $0.77(0.69-0.86)$ & $0.85(0.60-1.21)$ \\
\hline & $60-64$ & 1 (REF) & 1 (REF) \\
\hline Decade of MS & 1970 s & $0.98(0.78-1.22)$ & $1.36(0.78-2.39)$ \\
\hline \multirow[t]{3}{*}{ Diagnosis } & $1980 \mathrm{~s}$ & $1.02(0.89-1.19)$ & $0.75(0.47-1.19)$ \\
\hline & $1990 s$ & $0.94(0.83-1.07)$ & $0.90(0.62-1.30)$ \\
\hline & $2000 \mathrm{~s}$ & 1 (REF) & 1 (REF) \\
\hline \multirow[t]{2}{*}{ Marital status 2004} & Unmarried & $1.14(1.07-1.22)$ & $1.32(1.08-1.62)$ \\
\hline & Married & 1 (REF) & 1 (REF) \\
\hline \multirow[t]{3}{*}{ Education 2004} & $\leq 9$ years & $0.96(0.86-1.07)$ & $0.95(0.65-1.39)$ \\
\hline & $10-12$ years & $1.01(0.93-1.09)$ & $1.83(1.38-2.44)$ \\
\hline & $>12$ years & 1 (REF) & 1 (REF) \\
\hline \multirow[t]{2}{*}{ Previous psychiatric healthcare } & Yes & $2.32(2.18-2.47)$ & $1.91(1.59-2.30)$ \\
\hline & No & 1 (REF) & 1 (REF) \\
\hline
\end{tabular}


IRR: 1.77 (1.49-2.10). Unmarried individuals displayed higher risk for both psychiatric healthcare IRR: 1.14 $(1.07-1.22)$ as well as for suicidal behavior IRR: 1.32 (1.08-1.62).

In our sensitivity analyses, where we only included MS patients who recently were granted DP, we found similar risk estimates, IRR: 1.41(1.15-1.73) for psychiatric health care and IRR: 1.06 (0.46-2.43) for suicidal behavior (data not shown). Further, excluding MS patients with a history of psychiatric care yielded an IRR of 1.66 (1.27-2.16) for psychiatric health care (data not shown).

We performed effect-modification analyses to study if the IRRs were higher among people on DP regarding our socio-demographics and clinical factors (Tables 3 and 4). DP moderated the association between sex and psychiatric healthcare, where DP seemed to increase the risk for psychiatric healthcare more among women than among men, df $1, \mathrm{X}^{2} 4.74 \quad(p=0.03)$. No other significant effectmodifications were found $(\mathrm{p}<0.05)$.

\section{Discussion}

In this population-based prospective cohort study of 11 346 MS patients of working ages, we found that patients who were on DP in 2004 had a higher risk for psychiatric healthcare during the six-year follow up, whereas MS patients with previous psychiatric healthcare had a higher risk for both psychiatric healthcare and suicidal behavior. DP moderated (statistically significant) only the association between sex and psychiatric healthcare, where women on DP had higher risk for psychiatric healthcare during the follow-up than men.

The strengths of this study include the populationbased prospective cohort design, the large number of MS patients, and the use of high-quality and nationwide register data with high completeness and validity and no loss to follow up [13]. Our study also has some limitations. As out-patient visits were not included in the Patient register before 2001, the assumed decade of diagnosis might be later than the true one for those diagnosed before 2001, as many MS patients are not hospitalized and especially not at the time of diagnosis. We analyzed psychiatric healthcare (in-patient and specialized out-patient care), however, this does not cover all mental disorders, as primary health care visits are not included in the patient register. As this means that only the more severe mental disorders are included, this can be seen as both a limitation and as a strength. Furthermore, for the same reason, all suicidal behaviors are not noted in the registers since some acts of serious selfharming behavior do not lead to hospitalizations, specialized healthcare, or death. Moreover, some of the MS patients had been diagnosed a long time ago or been granted DP a long time ago. As the risks of suicide among MS patients are highest during the first year after
Table 3 Incidence rate ratios (IRR) with $95 \%$ confidence intervals (Cl) for psychiatric healthcare in 2005-2010 among 11 346 MS patients not on disability pension (DP) and on DP in 2004, respectively, regarding different background factors

\begin{tabular}{|c|c|c|c|c|}
\hline \multicolumn{5}{|c|}{ IRR for psychiatric health care ${ }^{a}$} \\
\hline & & No DP & DP & \\
\hline & & IRR $(95 \%$ Cl) & IRR $(95 \% \mathrm{Cl})$ & $\begin{array}{l}\text { Effect } \\
\text { modifications } \\
\text { X2 ( } p \text {-values) }\end{array}$ \\
\hline \multirow[t]{2}{*}{ Sex } & $\mathrm{F}$ & $1.00(0.90-1.11)$ & $1.15(1.05-1.26)$ & $\begin{array}{l}d f 1,4.74 \\
(0.03)\end{array}$ \\
\hline & M & 1 (REF) & 1 (REF) & \\
\hline \multirow[t]{3}{*}{$\begin{array}{l}\text { Country of } \\
\text { birth }\end{array}$} & Nordic & $1.02(0.67-1.55)$ & $0.95(0.72-1.25)$ & $\begin{array}{l}\text { df } 2,2.19 \\
(0.33)\end{array}$ \\
\hline & World & $0.91(0.68-1.21)$ & $1.09(0.87-1.37)$ & \\
\hline & Swe & 1 (REF) & 1 (REF) & \\
\hline \multirow{5}{*}{$\begin{array}{l}\text { Age } \\
\text { group } \\
2004\end{array}$} & $16-29$ & $1.30(1.03-1.65)$ & $1.65(1.26-2.17)$ & $\begin{array}{l}\text { df } 4,4.69 \\
(0.32)\end{array}$ \\
\hline & $30-39$ & $1.12(0.93-1.36)$ & $1.09(0.90-1.31)$ & \\
\hline & $40-49$ & $1.18(0.97-1.42)$ & $1.08(0.93-1.24)$ & \\
\hline & $50-59$ & $0.97(0.78-1.20)$ & $0.84(0.73-0.96)$ & \\
\hline & $60-64$ & 1 (REF) & 1 (REF) & \\
\hline \multirow{4}{*}{$\begin{array}{l}\text { Decade of } \\
\text { MS } \\
\text { diagnosis }\end{array}$} & 1970s & $1.20(0.78-1.84)$ & $0.87(0.67-1.13)$ & $\begin{array}{l}\text { df } 3,3.83 \\
(0.28)\end{array}$ \\
\hline & 1980s & $0.84(0.62-1.13)$ & $0.89(0.75-1.05)$ & \\
\hline & 1990s & $0.94(0.72-1.23)$ & $0.97(0.84-1.12)$ & \\
\hline & $2000 \mathrm{~s}$ & 1 (REF) & 1 (REF) & \\
\hline \multirow{2}{*}{$\begin{array}{l}\text { Marital } \\
\text { status } \\
2004\end{array}$} & $\begin{array}{l}\text { Not } \\
\text { married }\end{array}$ & 1 (REF) & 1 (REF) & $\begin{array}{l}\text { df } 1,1.05 \\
(0.30)\end{array}$ \\
\hline & Married & $0.96(0.86-1.06)$ & $1.02(0.95-1.11)$ & \\
\hline \multirow[t]{3}{*}{$\begin{array}{l}\text { Education } \\
2004\end{array}$} & $\leq 9$ years & $1.10(0.94-1.28)$ & $1.12(0.99-1.27)$ & $\begin{array}{l}\text { df } 2,4.98 \\
(0.08)\end{array}$ \\
\hline & $\begin{array}{l}10-12 \\
\text { years }\end{array}$ & $1.02(0.84-1.22)$ & $0.83(0.73-0.94)$ & \\
\hline & $>12$ years & 1 (REF) & 1 (REF) & \\
\hline
\end{tabular}

${ }^{a}$ The two models are adjusted for all main effects and the 6 interaction terms (i.e., effect-modifications) of interest

diagnosis [14] and many of our patients were diagnosed several years prior to 2004, this cohort could be seen as there was a 'health selection' of our study population regarding the studied outcomes, and thus an underestimation of the results. In the same manner, patients diagnosed earlier had a longer exposure time for psychiatric health and suicidal behavior care prior to the start of follow-up.

Here we compared MS patients on DP in 2004 with patients not on DP in 2004. However, the latter patients could have been granted DP during the follow-up that also means a possible underestimation of risks. Even so, MS patients on DP in 2004, showed higher IRR for psychiatric healthcare, but not statistically significant higher IRRs for suicidal behavior. MS patients with a history of 
Table 4 Incidence rate ratios (IRR) with 95 \% confidence intervals (CI) for future suicidal behavior (in 2005-2010) among 11346 MS patients not on disability pension (DP) and on DP in 2004, respectively, regarding different background factors

\begin{tabular}{|c|c|c|c|c|}
\hline \multicolumn{5}{|c|}{ IRR for suicidal behavior ${ }^{a}$} \\
\hline & & No DP & $\mathrm{DP}$ & \\
\hline & Level1 & IRR $(95 \%$ Cl) & IRR $(95 \% \mathrm{Cl})$ & $\begin{array}{l}\text { Effect modifications } \\
\text { X2 ( } p \text {-values) }\end{array}$ \\
\hline \multirow[t]{2}{*}{ Sex } & Female & $1.01(0.72-1.41)$ & $0.97(0.75-1.25)$ & df 1, $0.07(0.80)$ \\
\hline & Male & 1 (REF) & 1 (REF) & \\
\hline \multirow[t]{3}{*}{ Country of birth } & Nordic & $1.44(0.52-4.00)$ & $1.38(0.64-2.96)$ & df 2, $0.48(0.79)$ \\
\hline & World & $0.95(0.39-2.36)$ & $0.75(0.33-1.72)$ & \\
\hline & Sweden & 1 (REF) & 1 (REF) & \\
\hline \multirow[t]{5}{*}{ Age group 2004} & $16-29$ & $1.61(0.75-3.48)$ & $1.43(0.55-3.66)$ & df 4, $1.34(0.86)$ \\
\hline & $30-39$ & $0.95(0.39-2.36)$ & $0.88(0.47-1.65)$ & \\
\hline & $40-49$ & $1.48(0.80-2.74)$ & $1.13(0.72-1.77)$ & \\
\hline & $50-59$ & $0.73(0.31-1.69)$ & $0.91(0.59-1.38)$ & \\
\hline & $60-64$ & 1 (REF) & 1 (REF) & \\
\hline \multirow[t]{4}{*}{ Decade of diagnosis } & $1970 \mathrm{~s}$ & $0.00(0.00-0.00)$ & $1.70(0.95-3.03)$ & df $3,5.76(0.12)$ \\
\hline & $1980 \mathrm{~s}$ & 361.55 (89.46-1461.19) & $0.60(0.35-1.03)$ & \\
\hline & $1990 \mathrm{~s}$ & $224.66(149.36-337.92)$ & $0.88(0.58-1.32)$ & \\
\hline & $2000 \mathrm{~s}$ & 1 (REF) & 1 (REF) & \\
\hline Marital status & Not married & 1 (REF) & 1 (REF) & df 1, $0.13(0.71)$ \\
\hline 2004 & Married & $1.25(0.88-1.77)$ & $1.35(1.05-1.73)$ & \\
\hline \multirow[t]{3}{*}{ Education 2004} & $<=9$ years & $0.83(0.37-1.88)$ & $1.00(0.64-1.58)$ & df 2, $0.16(0.92)$ \\
\hline & $10-12$ years & $1.92(1.14-3.23)$ & $1.84(1.28-2.66)$ & \\
\hline & $>12$ years & 1 (REF) & 1 (REF) & \\
\hline
\end{tabular}

${ }^{a}$ The two models are adjusted for all main effects and the 6 interaction terms (i.e., effect-modifications) of interest

psychiatric ill health or suicide attempts might have a higher probability of being granted DP. This fact could in itself lead to higher risk of requiring specialized psychiatric healthcare after DP. We controlled for decade of diagnosis and previous specialized psychiatric healthcare in an attempt to reduce confounding, although these confounders are pretty obtuse which calls for cautious interpretation of our results and for further studies to compare these two groups as the residual confounding may be increased.

As we in this study lack data on cognitive and physical impairment, which are common consequences of MS $[15,16]$, one might argue that level of impairment could be responsible for both the probability of being granted DP and for the need of psychiatric health care. Although, the plausibility of this interpretation rests on the assumption that there is a positive association between impairment and need of psychiatric health care even after adjusting for prior psychiatric health care. This, however, is a questionable assumption since most longitudinal studies in which baseline psychiatric morbidity has been taken into account have not been able to reveal any associations between level of impairment and psychiatric morbidity [15-17].

Being on DP means that you are marginalized from the labor market, which might result in isolation, loss of meaning, change of life style, and loneliness that can affect the risk of suicidal behavior [18, 19]. It could, on the other hand, be argued that paid work among MS patients may involve stress that could increase the risk of mental disorders. In this study, the former seems to be true regarding psychiatric healthcare, and especially among women. A recent Swedish register study found a higher risk of premature death among young adults (1923 years) on DP, but only those with mental DP diagnoses had a significantly elevated risk for suicide [18].

Another Swedish study on trajectories of suicide attempt risks before and after granting of DP in young people, found a higher risk of suicide attempt up until the granting of DP, after which the risk decreased [20]. In our cohort of MS patients of all working ages, those on DP indicated higher risk for suicidal behavior (though not statistically significant), and "only" 118 MS patients had suicidal behavior during follow up in our study. Our 
data on this is thus limited and consequently our estimates had rather broad CIs. Even so, when analyzing psychiatric healthcare as outcome - an outcome related to suicidal behavior - the cohort included 1104 individuals and received similar estimates.

Not being married was one of the two factors that displayed higher risk for both outcomes. Unmarried individuals in the general population have previously been shown to have higher suicide risk, which is in line with our results [21]. A Danish study evaluated the probability of MS patients to remain married or in a relationship with the same partner after MS onset [22]. The cumulative probability of remaining in the same relationship five years after onset was $86 \%$ in MS patients vs. $89 \%$ in controls [22]. If the unmarried patients in our study had been previously married/ cohabiting needs to be further investigated. Having prior psychiatric healthcare was the other factor that entailed higher risk for both our outcomes. As mental disorder is the main risk factor for suicide [23], our result was expected. The most severe consequence of depression is suicide [23]. Around $30 \%$ of MS patients have reported suicide ideations [24]. A previous Swedish study found the suicide risk to be twice as high among MS patients as in the general population [14]. In this study, we did not compare suicidal behavior among MS patients with that in the general population, but compared suicidal behavior among MS patients with different socio-demographic and DP status in one year, 2004.

One general explanation of the association between lower educational level and suicidal behavior is the underlying elevated risk for mental disorders among less educated individuals [24]. In the general population it seems that mental disorder is a factor on the causal pathway between lower socio-economic position and suicidal behavior [25]. However, we found no such clear results for educational level for psychiatric healthcare or for suicidal behavior, probably as we controlled for prior psychiatric healthcare.

Existing literature on the general population has shown that women have higher risk for psychiatric healthcare [26], something we did not find in this cohort. Two previous studies found that men diagnosed with MS have a lower quality of life than women [27, 28]. Depression in MS patients has been suggested to be both part of the disease itself and to be a psychosocial reaction to the disease [29]. Estimations of depression prevalence among MS patients have fluctuated between 25-30 \%, nevertheless, only $25 \%$ of those patients received adequate antidepressant treatment from her/his neurologist [3]. The presence of depression does, however, not correlate well with the severity of the MS disease [30]. Depression impacts functional status and depressed MS patients perform more poorly on tests of cognitive function [31] which means that if depression is not optimally treated the risk of DP is higher.

DP only moderated the association between sex and psychiatric healthcare, which means that DP may be worse for women than for men regarding IRR for psychiatric healthcare. This finding needs, however, to be studied further.

\section{Conclusions}

In conclusion, our results suggest that MS patients on DP have higher future risk of requiring psychiatric healthcare than MS patients without DP, and especially younger patients are at risk. No significant higher risk was established in regard to suicidal behavior. DP also seems to involve higher risk for psychiatric healthcare among women. These findings suggest that losing one's role in work life aggravates rather than alleviates the burden of MS. Extra awareness among clinicians regarding MS patients on DP may be called for.

\section{Abbreviations}

DP: Disability pension; MS: Multiple sclerosis.

\section{Competing interests}

$\mathrm{JH}$ has over the years received honoraria for serving on advisory boards for Biogenldec and Novartis and speaker's fees from Biogenldec, Merck-Serono, Bayer-Schering, Teva Novartis, and Sanofi-Aventis. He has served as P.I. for projects, or received unrestricted research support from, Biogenldec, MerckSerono, TEVA, Sanofi-Aventis, and Bayer-Schering and is in the process of negotiating a research grant from Novartis.

\section{Authors' contributions}

PT, CB, and KA originated the idea. CB and PT performed the analyses. CB wrote the manuscript draft. All authors, CB, PT, PB, JH, EM, JJ, KA, contributed in the interpretation of the results and the writing and critical reviewing of the final manuscript. All authors read and approved the final manuscript.

\section{Acknowledgement}

This study was supported by unrestricted grants from Biogenldec, by the Swedish Research Council for Health, Working Life and Welfare (grant number 2007-1762), and the Swedish Research Council (Project numbers: K2009-61P-21304-04-4; K2009-61X-21305-01-1). The funders had no role in study design, data collection, analysis, decision to publish, or preparation of the manuscript.

\section{Author details}

${ }^{1}$ Division of Insurance medicine, Department of Clinical Neuroscience, Karolinska Institutet, SE-171 77 Stockholm, Sweden. ²Division of Neuroscience, Department of Clinical Neuroscience, Karolinska Institutet, Stockholm, Sweden.

Received: 22 January 2015 Accepted: 2 November 2015

Published online: 16 November 2015

\section{References}

1. Kobelt G, Berg J, Lindgren P, Fredrikson S, Jonsson B. Costs and quality of life of patients with multiple sclerosis in Europe. J Neurol Neurosurg Psychiatry. 2006;77(8):918-26.

2. Dean G. How many people in the world have multiple sclerosis? Neuroepidemiology. 1994;13(1-2):1-7.

3. Poser $C M$, Brinar $W$. The accuracy of prevalence rates of multiple sclerosis: a critical review. Neuroepidemiology. 2007;29(3-4):150-5.

4. Tinghog P, Hillert J, Kjeldgard L, Wiberg M, Glaser A, Alexanderson K. High prevalence of sickness absence and disability pension among multiple 
sclerosis patients: a nationwide population-based study. Mult Scler. 2013; 19(14):1923-30.

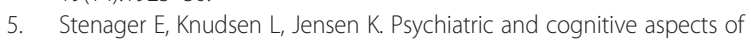
multiple sclerosis. Semin Neurol. 1990;10(3):254-61.

6. Stenager EN, Jensen B, Stenager M, Stenager K, Stenager E. Suicide attempts in multiple sclerosis. Mult Scler. 2011;17(10):1265-8.

7. Stenager EN, Stenager E, Koch-Henriksen N, Bronnum-Hansen $H$, Hyllested K, Jensen K, et al. Suicide and multiple sclerosis: an epidemiological investigation. J Neurol Neurosurg Psychiatry. 1992; 55(7):542-5.

8. Weiss DB, Dyrud J, House RM, Beresford TP. Psychiatric manifestations of autoimmune disorders. Curr Treat Options Neurol. 2005;7(5):413-7.

9. Kingwell E, Marriott JJ, Jette N, Pringsheim T, Makhani N, Morrow SA, et al. Incidence and prevalence of multiple sclerosis in Europe: a systematic review. BMC Neurol. 2013;13:128.

10. Raskind MA. Diagnosis and treatment of depression comorbid with neurologic disorders. Am J Med. 2008;121(11 Suppl 2):S28-37.

11. Ludvigsson JF, Otterblad-Olausson P, Pettersson BU, Ekbom A. The Swedish personal identity number: possibilities and pitfalls in healthcare and medical research. Eur J Epidemiol. 2009;24(11):659-67. Epub 2009/06/09.

12. Linsley KR, Schapira K, Kelly TP. Open verdict v. suicide - importance to research. Br J Psychiatry. 2001;178:465-8.

13. Ludvigsson JF, Andersson E, Ekbom A, Feychting M, Kim JL, Reuterwall C, et al. External review and validation of the Swedish national inpatient register. BMC Public Health. 2011;11:450. Epub 2011/06/11.

14. Fredrikson S, Cheng Q, Jiang GX, Wasserman D. Elevated suicide risk among patients with multiple sclerosis in Sweden. Neuroepidemiology. 2003;22(2):146-52.

15. Brown RF, Valpiani EM, Tennant CC, Dunn SM, Sharrock M, Hodgkinson $S$, et al. Longitudinal assessment of anxiety, depression, and fatigue in people with multiple sclerosis. Psychol Psychother. 2009;82(Pt 1):41-56. Epub 2008/08/30.

16. Bruce AS, Arnett PA. Longitudinal study of the symptom checklist 90-revised in multiple sclerosis patients. Clin Neuropsychol. 2008;22(1):46-59. Epub 2008/03/14.

17. Janssens AC, Buljevac D, van Doorn PA, van der Meche FG, Polman CH, Passchier J, et al. Prediction of anxiety and distress following diagnosis of multiple sclerosis: a two-year longitudinal study. Mult Scler. 2006;12(6):794-801. Epub 2007/02/01.

18. Jonsson U, Alexanderson K, Kjeldgard L, Westerlund H, Mittendorfer-Rutz E. Diagnosis-specific disability pension predicts suicidal behaviour and mortality in young adults: a nationwide prospective cohort study. BMJ open. 2013;3(2). Epub 2013/02/12.

19. Vingard E, Alexanderson K, Norlund A. Swedish Council on Technology Assessment in Health Care (SBU). Chapter 9. Consequences of being on sick leave. Scand J Public Health Suppl. 2004;63:207-15. Epub 2004/10/30.

20. Mittendorfer-Rutz E, Alexanderson $\mathrm{K}$, Westerlund H, Lange T. Is transition to disability pension in young people associated with changes in risk of attempted suicide? Psychol Med. 2014;44(11):1-8.

21. Miret M, Caballero FF, Huerta-Ramirez R, Moneta MV, Olaya B, Chatterji S, et al. Factors associated with suicidal ideation and attempts in Spain for different age groups. Prevalence before and after the onset of the economic crisis. J Affect Disord. 2014;163:1-9.

22. Pfleger CC, Flachs EM, Koch-Henriksen N. Social consequences of multiple sclerosis. Part 2. Divorce and separation: a historical prospective cohort study. Mult Scler. 2010;16(7):878-82.

23. Harris EC, Barraclough B. Suicide as an outcome for mental disorders. A meta-analysis. Br J Psychiatry. 1997;170:205-28.

24. Burrows S, Laflamme L. Socioeconomic disparities and attempted suicide: state of knowledge and implications for research and prevention. Int J Inj Control Saf Promot. 2010;17(1):23-40.

25. Cubbin C, Smith GS. Socioeconomic inequalities in injury: critical issues in design and analysis. Annu Rev Public Health. 2002;23:349-75.

26. Kessler RC, Berglund P, Demler $O$, Jin R, Merikangas KR, Walters EE. Lifetime prevalence and age-of-onset distributions of DSM-IV disorders in the National Comorbidity Survey Replication. Arch Gen Psychiatry. 2005;62(6): 593-602. Epub 2005/06/09

27. Casetta I, Riise T, Wamme Nortvedt M, Economou NT, De Gennaro R, Fazio $P$, et al. Gender differences in health-related quality of life in multiple sclerosis. Mult Scler. 2009;15(11):1339-46.
28. Miller A, Dishon S. Health-related quality of life in multiple sclerosis: The impact of disability, gender and employment status. Qual Life Res. 2006; 15(2):259-71.

29. Arnett PA, Barwick FH, Beeney JE. Depression in multiple sclerosis: review and theoretical proposal. J Int Neuropsychol Soc. 2008;14(5):691-724.

30. Goldman CG. The Goldman Consensus statement on depression in multiple sclerosis. Mult Scler. 2005;11(3):328-37.

31. Gilchrist AC, Creed FH. Depression, cognitive impairment and social stress in multiple sclerosis. J Psychosom Res. 1994;38(3):193-201.

\section{Submit your next manuscript to BioMed Central and take full advantage of:}

- Convenient online submission

- Thorough peer review

- No space constraints or color figure charges

- Immediate publication on acceptance

- Inclusion in PubMed, CAS, Scopus and Google Scholar

- Research which is freely available for redistribution 